\title{
Head Injuries in Skiers and Snowboarders in British Columbia
}

\author{
Stephen Hentschel, Walter Hader, Michael Boyd
}

\begin{abstract}
Background: At the Vancouver General Hospital Neurosurgical Service there have been a significant number of seriously brain injured snowboarders, seemingly out of proportion to the number of skiers. The purpose of this study was to determine whether snowboarders suffered more serious head injuries than skiers in the Vancouver catchment area. Methods: The British Columbia Trauma Registry was searched for patients incurring head injuries while skiing or snowboarding on British Columbia mountains during the period from January 1992 to December 1997. Patients were included if they were admitted to hospital and underwent neurosurgical consultation. Results: A total of 40 skiers and 14 snowboarders met the above criteria. Of the skiers, $15 \%$ sustained a severe head injury by Glasgow Coma Score, another 30\% sustaining moderate head injuries, while $29 \%$ of snowboarders had a severe injury and $36 \%$ a moderate injury. A concussion was present in $60 \%$ of the skiers and $21 \%$ of the snowboarders. Snowboarders suffered an intracranial hemorrhage in $71 \%$ of the cases compared to $28 \%$ of the skiers. A craniotomy was performed acutely in $10 \%$ of skiers and in $29 \%$ of snowboarders. Three deaths occurred as a direct result of head injury, one while snowboarding. All but one of the surviving skiers were able to return home, whereas four of 13 surviving snowboarders required additional inpatient rehabilitation or transfer to another acute hospital for ongoing care. Conclusions: Snowboarders suffer more significant head injuries compared to skiers in this series and are much more likely than skiers to require an intracranial procedure. In our opinion, this indicates that additional safety measures, in particular the use of mandatory helmets, should be considered by ski areas and their patrons.
\end{abstract}

RÉSUMÉ: Traumatismes crâniens chez les skieurs et les adeptes de la planche à neige en Colombie-Britannique. Introduction: Le service de neurochirurgie du Vancouver General Hospital a reçu un nombre adeptes de la planche à neige souffrant de blessures sérieuses à la tête hors de proportion avec celui des skieurs présentant de telles blessures. Le but de cette étude était de déterminer si les adeptes de la planche à neige avaient plus de blessures sérieuses à la tête que les skieurs dans la région desservie par Vancouver. Méthodes: Le registre des traumatismes de la ColombieBritannique a été consulté pour identifier les patients qui avaient subi des blessures à la tête en ski ou en planche à neige dans les centres de sports d'hiver de la Colombie-Britannique pendant la période de janvier 1992 à décembre 1997. Les patients étaient inclus dans l'étude s'ils étaient admis à l'hôpital et avaient eu une consultation en neurochirurgie. Résultats: Au total, 40 skieurs et 14 adeptes de la planche à neige rencontraient les critères décrits ci-haut. Parmi les skieurs, $15 \%$ avaient subi une blessure sévère à la tête selon le score GCS et 30\% avaient subi une blessure modérée, par rapport à $29 \%$ des adeptes de la planche à neige qui avaient subi des blessures sévères et $36 \%$ des blessures modérées. $60 \%$ des skieurs et $21 \%$ des adeptes de la planche à neige avaient subi une commotion cérébrale. Les adeptes de la planche à neige avaient subi une hémorragie intracrânienne dans $71 \%$ des cas par rapport à $28 \%$ des skieurs. Une crâniotomie a été effectuée en urgence chez $10 \%$ des skieurs et $29 \%$ des adeptes de la planche à neige. Trois patients sont décédés de leurs blessures à la tête, dont un adepte de la planche à neige. Tous sauf un des skieurs survivants ont pu retourner chez eux, alors que quatre des 13 adeptes de la planche à neige survivants ont eu besoin de réhabilitation additionnelle pendant leur séjour à l'hôpital ou d'un transfert à un autre hôpital de soins aigus. Conclusions: Dans cette série de cas, Les adeptes de la planche à neige ont subi plus de blessures sévères à la tête que les skieurs et sont plus susceptibles que les skieurs d'avoir besoin d'une intervention intracrânienne. À notre avis, ceci indique que des mesures de sécurité additionnelles, surtout quant au port obligatoire du casque, devraient être considérées par les centres de ski et leurs clients.

Can. J. Neurol. Sci. 2001; 28: 42-46

There have been several reports in recent years that have studied and compared injuries sustained while downhill skiing ${ }^{1,2}$ or snowboarding. ${ }^{3-9}$ Some have concentrated on central nervous system injuries in skiers and snowboarders; ${ }^{10-12}$ however, only one has specifically addressed the severity of head injuries in this population. $^{13}$

British Columbia (BC) has become a major destination for skiers and snowboarders during the last several years resulting in an increased number of persons skiing each year. Concurrent with this, there has been a perceived increase in the quantity and severity of ski and snowboarding injuries admitted to the five Vancouver area hospital neurosurgical services. The purpose of this study was to determine the number and severity of ski and snowboard related head injuries requiring neurosurgical management in the Vancouver area and to compare these two groups.

From the Division of Neurosurgery, Department of Surgery, University of British Columbia, Vancouver Hospital and Health Sciences Center, Vancouver, British Columbia, Canada

ReCEIVED MARCh 29, 2000. ACCEPTEDIN FinALFORM November 27, 2000. Reprint requests to: Stephen Hentschel, Department of Surgery, Division of Neurosurgery, 3rd Floor, 910 West 10th Avenue, Vancouver, BC V5Z 4E3 Canada 


\section{Methods}

The trauma database (BC Trauma Registry) was searched for patients who suffered head injuries while skiing or snowboarding on the five local BC mountains during the period from January 1992 to December 1997. Patients were included in this study if they met the following criteria: 1) suffered a head injury that required neurosurgical consultation, 2) the injury occurred while skiing or snowboarding, 3) the injury occurred on a BC mountain and 4) the patient was admitted to one of the five centers in Vancouver with a neurosurgical service. The hospital record was reviewed for information regarding circumstances of the injury, initial Glasgow Coma Score (GCS), CT scan results, injuries sustained, treatments provided and condition on discharge.

The initial GCS score was taken to be the score that was first recorded after appropriate initial resuscitation. This was usually obtained by the attending mountain physician or by trained ambulance personnel. Head injuries were classified as either being minor (GCS 14-15), moderate (GCS 8-13), or severe (GCS $<8$ ). A concussion was felt to have occurred when a patient sustained a mild head injury with a normal CT scan of the head, with or without associated skull fractures. The outcomes were recorded as the patient's status at the time of discharge from hospital.

Unfortunately, the ski areas do not record the relative proportion of skiers and snowboarders and thus an estimate of $70 \%$ skiers and $30 \%$ snowboarders was made by the main resort areas reported in the study for use in the calculation of head injury rates.

\section{RESUlts}

\section{Patient population}

Fifty-four patients, 40 skiers and 14 snowboarders were included in the study (see Table 1). The age range was 9-73 years. Snowboarders had a younger median age (22 years) compared to skiers (32 years). Eleven patients (20\%) were female (14\% of snowboarders, $23 \%$ of skiers). The most common mechanism of injury was a fall on the mountain. Injuries sustained while jumping occurred in six skiers and two snowboarders. There were a total of $8,728,095$ skier and/or snowboarders at the two main ski areas included in this study during the reported time period. The head injury rates at these areas were 0.005 per 1000 for skiers and 0.004 per 1000 for snowboarders. The other ski areas were not included in this calculation due to the small numbers contributed by these locations. Five skiers and two snowboarders were specifically recorded as not wearing helmets, the rest were unspecified.

\section{Severity of injury}

A concussion was the most common injury among skiers, occurring in $24(60 \%)$ of these patients, compared to only three $(21 \%)$ in the snowboarding group (see Table 2). There were 10 severe head injuries, occurring in six $(15 \%)$ skiers and four (29\%) snowboarders. Seventeen patients had a moderate head injury, including $12(30 \%)$ of the skiers and five $(36 \%)$ of the snowboarders. Another 27 patients had mild head injuries, found in $22(55 \%)$ skiers and five $(36 \%)$ snowboarders. The average GCS score for skiers was 12 and for snowboarders it was 11 .
Table 1: Population Demographics

\begin{tabular}{lrcr}
\hline & Skiers & Snowboarders & Total \\
Number & 40 & 14 & 54 \\
Age: (years) & & & \\
$\quad$ Range & $9-73$ & $13-37$ & $9-73$ \\
$\quad$ Median & 32 & 22 & 27 \\
& & & \\
Sex: & 9 & 2 & 11 \\
$\quad$ Female & 31 & 12 & 43 \\
$\quad$ Male & & & \\
& & & \\
Mechanism & 13 & 0 & 15 \\
$\quad$ hit tree & 14 & 8 & 22 \\
$\quad$ hit another skier & 6 & 2 & 8 \\
$\quad$ fell on hill & 1 & 2 & 3 \\
$\quad$ fell while jumping & & 0 & 2 \\
$\quad$ ran into an object & 1 & 0 & 2 \\
$\quad$ fell off chair lift & 2 & & \\
$\quad$ uncertain & 2 & & \\
\hline
\end{tabular}

Fourteen $(35 \%)$ of the skiers had skull fractures, four linear, eight basal, and two depressed. A higher incidence of fractures was present in the snowboarders with nine (64\%) skull fractures, two linear, five basal, and two depressed.

\section{Intracranial pathology}

The most common single intracranial pathology was diffuse axonal injury, demonstrated by shear hemorrhages and cerebral edema, occurring in 13 (24\%) patients in total. Ten (25\%) of the skiers and three $(21 \%)$ of the snowboarders sustained such an injury. Twenty-one (39\%) patients, $11(28 \%)$ skiers and $10(71 \%)$ snowboarders, had a hemorrhagic lesion on CT scan (other than a shear hemorrhage). The most common such lesion was a cerebral contusion, being present in $12(22 \%)$ patients, with a further nine $(17 \%)$ having epidural hematomas, four $(7 \%)$ having subdural hematomas and four $(7 \%)$ with traumatic subarachnoid hemorrhages. Note that different types of hematoma may have been present in a single patient. See Table 2 for a breakdown of the head injuries.

\section{Intracranial procedures}

Overall, eight craniotomies were performed, four (10\%) in skiers and four (29\%) in snowboarders (see Table 3). In skiers, craniotomies were performed for one epidural hematoma, one depressed skull fracture, and one intracerebral contusion. One further craniotomy was performed for a CSF leak resulting from a basal skull fracture. Two snowboarders required a craniotomy to evacuate an epidural hematoma and another two required operation for depressed skull fractures. Two snowboarders had insertion of an external ventricular drain for intracranial pressure (ICP) management and one had burr holes for a chronic subdural hematoma. Two significantly debilitated patients, one in each group of patients, required tracheostomy and gastric tube insertions. Table 3 lists the other procedures performed on these patients. 


\section{Table 2: Injuries Sustained}

\begin{tabular}{lrrr}
\hline Initial GCS score: & Skiers & Snowboarders & Total \\
$\quad 3-7$ & & & \\
$8-13$ & 6 & 4 & 10 \\
$14-15$ & 22 & 5 & 17 \\
average & 12 & 11 & 27 \\
& & & 12 \\
Injuries: & & & \\
linear skull fracture & 4 & 2 & 6 \\
basal skull fracture & 8 & 5 & 13 \\
CSF leak & 4 & 2 & 6 \\
depressed skull fracture & 2 & 2 & 4 \\
cerebral contusion & 6 & 6 & 12 \\
epidural hematoma & 5 & 4 & 9 \\
subdural hematoma & 2 & 2 & 4 \\
diffuse/axonal shear & 10 & 3 & 13 \\
hemorrhage NOS & 3 & 1 & 4 \\
concussion & 24 & 3 & 27 \\
$\quad$ spine & 8 & 3 & 11 \\
Head injury rate (per 1000) & 0.005 & 0.004 &
\end{tabular}

\section{Outcome}

Two skiers died from their head injuries, one from a severe diffuse head injury and another from a large epidural hematoma. Two other patients died with what appeared to be minor head injuries (on CT scan), one from massive cerebral infarction secondary to bilateral carotid dissections with occlusion, and the other from anoxic injury secondary to respiratory arrest with abdominal and thoracic trauma. A fifth skier, with a high complete cervical cord injury, died after a prolonged stay in hospital when his ventilator was disconnected at his request (he had initially sustained a mild head injury). The one snowboarder who died suffered a severe head injury resulting in brain death.

All but three $(92 \%)$ of the injured skiers (including the two patients who suffered fatal head injuries) were able to return home, with only one requiring further inpatient rehabilitation (see Table 4); the three patients who died of nonhead injury related causes were excluded from this analysis. However, only nine $(64 \%)$ of the snowboarders were able to return home directly on discharge, while $4(29 \%)$ required ongoing inpatient rehabilitation. Most (83\%) of the surviving skiers were neurologically normal upon leaving hospital, compared to only $54 \%$ of the snowboarders. Mild dysfunction included symptoms of 'postconcussion syndrome', persistent headaches, significant fatigue and mild concentration or memory problems. Patients with significant impairment had difficulties with the basic activities of daily living. Three snowboarders had significant impairment on discharge whereas none of the skiers did.

Both the hospital stay and intensive care unit stays were longer for the snowboarders with an average stay of 20.4 days on the ward and 11.8 days in the ICU while for skiers it was 6.6 days and 4.7 days, respectively. One patient in each group with a very prolonged stay artificially inflated both groups'averages.

\section{Discussion}

\section{Severity of head injuries}

Head injuries associated with recreational skiing and snowboarding are uncommon but represent a significant cause of morbidity and mortality. There has only been one previous report looking specifically at head injuries in snowboarders and skiers. ${ }^{13}$ Most studies to date have only addressed head injuries as a subgroup of a larger multiple trauma population concerning snowboard and ski related injuries. Prall et al, ${ }^{6}$ who reported on severe snowboarding injuries, found intracranial hemorrhages in $25 \%$ of snowboarders and $31 \%$ of skiers out of the patients who had head injuries, none of which required an ICP monitor or a craniotomy. His patient population consisted of patients requiring referral to a level I trauma center and thus would be expected to include the most severely head injured patients. From his data, it can be calculated that the head injury rate in skiers and snowboarders was 0.008 and 0.016 per 1000 , respectively. Our reported head injury rates are expected to be lower than this due to the restricted population in this study. What is quite different about our data is the much higher incidence of snowboarder intracranial hemorrhage (71\% vs. $25 \%$ ). Another study found 16 intracranial hemorrhages in 88 head injured downhill skiers, for an incidence of $18 \%{ }^{11}$ Their patient population was quite similar to the one that we are reporting upon, with selection criteria including requirement for neurosurgical consultation and admission to hospital.

In a study by Myles et $\mathrm{al}^{11}$ that included all central nervous system injuries, there was a total of 88 head injuries over a five year period. He reported $70(80 \%)$ of these injuries as concussions, which he defined as a "transient loss of consciousness due to an impact". Prall et $\mathrm{al}^{6}$ reported a similar concussion rate of $65 \%$ in snowboarders and $46 \%$ in skiers. Contrary to his findings, skiers in our series were noted to have a concussion $60 \%$ of the time while only $21 \%$ of the snowboarders sustained a concussion, the rest sustaining a more serious injury.

Skull fractures occurred nearly twice as often as in skiers. Intracranial hemorrhages occurred 2.5 times more frequently in snowboarders than in skiers. Although some of these did not

Table 3: Procedures

\begin{tabular}{lccc}
\hline & Skiers & Snowboarders & Total \\
Craniotomy: & 4 & 4 & 8 \\
$\quad$ evacuation epidural hematoma & 1 & 2 & 3 \\
$\quad$ evacuation subdural hematoma & 0 & 0 & 0 \\
$\quad$ elevation skull fracture & 1 & 2 & 3 \\
$\quad$ other & 2 & 0 & 2 \\
ICPmonitor & 0 & 2 & 2 \\
Burr holes & 0 & 1 & 1 \\
Cerebral angiography & 2 & 0 & 2 \\
Laparotomy & 2 & 1 & 3 \\
Tracheostomy & 1 & 1 & 2 \\
G-tube & 1 & 1 & 2
\end{tabular}


Table 4: Outcomes

\begin{tabular}{|c|c|c|c|}
\hline & Skiers & Snowboarders & Total \\
\hline $\begin{array}{c}\text { Length of hospital stay (c } \\
\text { ward or stepdown } \\
\text { (median/average) }\end{array}$ & $4 / 6.6$ & $9 / 20.4$ & $5 / 8$ \\
\hline ICU & & & \\
\hline (median/average) & $\begin{array}{c}1 / 4.7 \\
13 / 40 \text { patients) }\end{array}$ & $\begin{array}{c}8 / 11.8 \\
\text { (6/14 patients)( }\end{array}$ & $\begin{array}{c}3 / 5 \\
8 / 54 \text { patients) }\end{array}$ \\
\hline
\end{tabular}

Status on discharge:

$\begin{array}{lccc}\text { intact } & 29 & 7 & 36 \\ \text { mild dysfunction } & 6 & 3 & 9 \\ \text { significant impairment } & 0 & 3 & 3 \\ \text { deceased } & 5 & 1 & 6\end{array}$

Destination on discharge:

$\begin{array}{lccc}\text { home } & 34 & 9 & 43 \\ \text { rehab centre } & 1 & 3 & 4 \\ \text { another acute hospital } & 0 & 1 & 1 \\ \text { deceased } \quad \text { from a head injury } & 2 & 1 & 6 \\ \quad \text { from other injuries } & 3 & 1 & 3 \\ \end{array}$

require surgical intervention, the fact that $29 \%$ of snowboarders and only $10 \%$ of skiers required a craniotomy lends further support to the more serious nature of snowboarder injuries. There were no skiers who had an intracranial pressure monitoring device placed, while two snowboarders required external ventricular drainage for management of raised ICP. A study from Japan found a significantly higher incidence of major head injury (defined as a positive CT scan) in snowboarders (6.3\% of all head injuries) compared with skiers $(1.3 \%) .{ }^{13}$

Given that our patient population is so highly selected to represent the most severely head injured but surviving patients, it is difficult to compare with most previous studies. Our findings suggest that snowboarders suffered more serious brain injuries than did skiers during the time period included in this study. Most other authors have found that skiers and snowboarders suffer relatively similar head injuries in terms of the severity. ${ }^{3,8}$ Prall et $\mathrm{al}^{6}$ found that snowboarders had a somewhat higher incidence of head injuries (54\% compared to $40 \%$ in skiers) but most of the injuries in snowboarders were concussions and skiers actually suffered the more significant head injuries by a small margin. It may be that these prior studies either were not able to analyze enough skier and snowboarder head injuries specifically and thus were not able to identify a difference between the two groups, or it may be that our study has identified a more recent trend in the pattern of injury in these groups. This may be reflective of the rapidly increasing popularity of snowboarding.

\section{Predisposing factors}

The possible reasons for snowboarders having more serious brain injuries than skiers are multiple. Firstly, the snowboarding population is perhaps already preselected by being younger, more likely male, more adventurous, and more likely to engage in potentially dangerous activities. The second reason, which we were not able to address in this study but has been previously reported, is that snowboarders are more likely to be beginners and thus more likely to be injured. ${ }^{3,9,13}$ The third reason, for which we have no proof, is that the mechanics of snowboarding predispose one to head injuries.

\section{Limitations of the study}

This small retrospective study precludes any statistical analysis and the potential for incomplete data is inherent. Stringent criteria for entry into this study may exclude a significant number of head injured skiers and snowboarders and therefore underestimate true head injury rates. Several reasons exist to explain the seemingly disproportionate number of seriously injured snowboarders as compared to skiers. It is possible that skiers suffer more serious fatal head injuries, do not survive long enough to reach hospital and therefore escape analysis through hospital data bases. Alternatively, a younger snowboarder with a more mild head injury such as concussion, may not seek medical attention, and therefore only the most serious head injuries would result in referral, neurosurgical consultation, and admission. Age and sex are confounding variables in this study. However, in this observational study, we feel that rather than invalidate the observations, younger age and male sex further define the population at risk.

The fact that no patient was recorded to have been wearing a helmet at the time of injury does not, of course, mean that no helmets were worn at the time of injury. However, in our experience, helmet use during this time period would be quite uncommon for the ski areas reported in this study.

\section{CONCLUSIONS}

Snowboarders with head injuries in this series had more serious intracranial injuries, required an intracranial procedure at a much higher rate, had overall longer hospital and intensive care unit stay, and had worse functional outcomes than did skiers during the same time period. In our opinion, serious consideration needs to be given to this matter given that snowboarding is becoming increasingly popular. Increased awareness through education as well as mandatory helmets and/or lessons prior to undertaking these potentially dangerous activities may help to reduce the number of serious head injuries.

\section{ACKNOWLEDGEMENTS}

We thank Sharon Kasic, Manager, and Dr. Richard Simons, Medical Director, of the BC Trauma Registry as well as Susan Sirett of VGH medical records for their help in obtaining the data for the patients in this study.

\section{REFERENCES}

1. Davidson TM, Laliotis AT. Alpine skiing injuries. A nine-year study. West J Med 1996; 164:310-314.

2. Furrer M, Erhart S, Frutiger A, et al. Severe skiing injuries: a retrospective analysis of 361 patients including mechanism of trauma, severity of injury, and mortality. J Trauma 1995; 39:737741.

3. Abu-Laban RB. Snowboarding injuries: an analysis and comparison with alpine skiing injuries. Can Med Assoc J 1991; 145:10971103.

4. Bladin C, McCrory P. Snowboarding injuries. An overview. Sports Med 1995; 19:358-364. 
5. Chow TK, Corbett SW, Farstad DJ. Spectrum of injuries from snowboarding. J Trauma 1996; 41:321-325.

6. Prall JA, Winston KR, Brennan R. Severe snowboarding injuries. Injury $1995 ; 26: 539-542$.

7. Davidson TM, Laliotis AT. Snowboarding injuries, a four-year study with comparison with alpine ski injuries. West J Med 1996; 164:231-237.

8. Sacco DE, Sartorelli DH, Vane DW. Evaluation of alpine skiing and snowboarding injury in a northeastern state. J Trauma 1998; 44:654-659.

9. Sutherland AG, Holmes JD, Myers S. Differing injury patterns in snowboarding and alpine skiing. Injury 1996; 27:423-425.

10. Kip P, Hunter RE. Cervical spine fractures in alpine skiers. Orthopedics 1995; 18:737-741.

11. Myles ST, Mohtadi NGH, Schnittker J. Injuries to the nervous system and spine in downhill skiing. Can J Surg 1992; 35:643647.

12. Prall JA, Winston KR, Brennan R. Spine and spinal cord injuries in downhill skiers. J Trauma 1995; 39:1115-1118.

13. Nakaguchi H, Fujimaki T, Ueki K, et al. Snowboard head injury: prospective study in Chino, Nagano, for two seasons from 1995 to 1997 . J Trauma $1999 ; 46: 1066-1069$. 